\title{
IS THE GROWING USE OF ELECTRONIC DEVICES BENEFICIAL TO ACADEMIC PERFORMANCE? RESULTS FROM ARCHIVAL DATA AND A SURVEY
}

\author{
Taylor S. Drain, Washburn University, taylor.drain@washburn.edu \\ Lakeisha E. Grier, Washburn University, lakeisha.grier@washburn.edu \\ Wenying Sun, Washburn University,nan.sun@washburn.edu
}

\begin{abstract}
In this study, we investigate the relationship between academic performance and the use of computer technology. We test our hypothesis which proposes that the growing use of electronic deveices is academically beneficial to high school students' standardized test scores and GPA. Our method of data collection includes both a survey of high school students in the Midwest area and an analysis of national SAT scores in the years before computing and in years with computing. Analysis of SAT archival data shows a negative correlation between scores pre-computing and scores post-computing (with computing influences), meaning that as scores before computing were decreasing, scores with prevalent computer technology are increasing. Our survey data also displayed a positive correlation between time spent on electronic devices for school purpose and GPA.
\end{abstract}

Keywords: Computer Technology, Academic Performance, SAT, GPA, Electronic Devices

\section{INTRODUCTION}

The availability and use of electronic devices continues to grow. Over 420 million smart phones were sold worldwide in 2011 [6]. Almost 400 million computers were sold during 2010, and that figure is expected to increase to over 1 billion units which will include computers and smart phones by 2014 [3]. With the development of Wi-Fi hotspots, it is now easier for people to stay connected with their portable devices. Since electronic devices continue to be adapted to be friendlier to the end users, we want to research how the increased use of computer based technologies both in the classroom and at home impacts the academic performance of students.

The following research question is posed: "Is the increased use of computer based technology improving the academic performance of students?" In order for us to investigate this question, we have analyzed two sources of data. The first being SAT test scores over the last 30 years. The second source is from data we collected from a survey that we presented to high school students.

This study is important because it shows that the increasing use of electronic technologies for schoolwork is improving students' academic performance. Computer technology is everywhere in the society, and most of the high school students in the U.S. own or have access to computer technology on a daily basis. We hope to show appropriate use of these technologies will increase learning.

The remainder of the paper is organized as follows. We provide a literature review on related research. We then discuss the data analysis and present the results. The last section provides discussions of the results along with the implications of this study.

\section{LITERATURE REVIEW}

Our literature review suggests there are contradictory conclusions from various studies regarding whether computer use improves academic performance. Some studies state that computer use improves academic performance. Others propose that academic performance has nothing to do with computer use. A few studies suggest that computer use is a distraction to school studies and negatively impacts academic performance. 


\section{Issues in Information Systems}

Volume 13, Issue 1, pp. 225-231, 2012

One study claims that there exists evidence that Internet-time is harming children's academic performance. This study was done by economists at the University of Munich named Thomas Fuchs and Ludger Woessmann who surveyed students in 31 countries. They created a very thorough, detailed survey in order to eliminate other possible causes of the downward trend of academic performance. They state in their results that the "sheer ubiquity of information technology is getting in the way of learning" [7].

Another study hoped to find correlation in Internet/ Gaming Use and its numerous effects on adolescents. They analyzed not just academic performance, but social skills, relationships, sense of reality and violent behavior. Their conclusion regarding internet use and its impact on academic performance was "although playing specific computer games has immediate positive effects on specific spatial, iconic, and attentional skills used by the game, we need more research to see if long term computer and Internet use (both game and nongame) can lead to long term improvements in cognitive skills and academic achievement" [8].

Another study investigated the relationship between academic achievement and computer use. The focus was students in the $10^{\text {th }}$ grade. They did a survey of three high schools in Ohio. This study had the students keep a log of how much time they used the computer for several different categories of activities. The study did not focus on any testing scores. Everything was measured against the students GPA. It did not find computer use at home and GPA to have a significant relationship [5].

A final study analyzed the impact of owning a computer at home and not necessarily using it to assist in the classroom. They concluded that "home computers are associated with a 6-8 percentage point higher probability of graduating from high school" [2]. They also discussed that their statistics supported the idea that owning a personal computer or having access to one at home had a positive correlation with grades and a negative correlation with suspension. While many studies, experiments and discussions continue to dwell around this topic, we will specifically analyze the impact of computer technology on high school students' standardized test scores and determine if we can further support the idea that computing benefits learning.

\section{RESEARCH METHODOLOGY}

We gathered data from two sources. One was external and compiled from publicly reported standardized test scores. The second was collected from a survey of high school students we conducted. Our first data source is compiled ACT and SAT scores from their respective institutions statistical data archives. [1,4] We have access to ACT scores from 1994 to 2011 and SAT scores from $1978-2011$.

SAT scores were not separated by state until 1998. We choose one state from each of the following regions to represent the United States: Midwest (Kansas), New England (Massachusetts), Southwest (Texas), Pacific Coast (California), Southeast (Florida), Mid-Atlantic (New York). We chose Kansas to represent the Midwest, as we knew our survey data would be gathered from that state. As for selecting representative states for the other regions, we took into consideration that we wanted the most general, unbiased data. Therefore we selected states with the largest populations in hopes that those who took the standardized tests would be a more thorough and accurate sample of that state.

Prior to 2005 , the SAT did not contain a writing section to the standardized assessment. In order to make our data comparable, we only compared the verbal and math scores for all the years we analyzed. We took the mean of the SAT, per year, per region (state), to the mean of the GPA that is recorded that year. For the ACT, we compared the scores for each year, for each region, to the national mean of that year and observed the trends present. We determined ACT data to be unusable for our study due to the fact that the years and breakdown of the scores was very limited.

Our second source of data is the responses from a survey that were distributed to high school students in the Midwest area. We took several steps to conduct this survey. First, we designed the survey instrument. This included several rounds of determining more refined questions and formatting for the best presentation. Our survey questions were divided into two categories. One category was general demographic information including: gender, age, and 


\section{Issues in Information Systems \\ Volume 13, Issue 1, pp. 225-231, 2012}

grade level. After looking at common survey questions, we were able to word these basic demographic questions to be clear and concise. The other category included data that would directly relate to our theory: GPA, SAT score, ACT score, time spent on computer for entertainment, school, and other purposes. In order to eliminate potential human error problems or difficulty reading participants' answers, we provided answers with checkboxes for every question except for the computer usage question.

Our survey questions were divided into two categories. One category was general demographic information including: gender, age, and grade level. After looking at common survey questions, we were able to word these basic demographic questions to be clear and concise. The other category included data that would directly relate to our theory: GPA, SAT score, ACT score, time spent on computer for entertainment, school, and other purposes. In order to eliminate potential human error problems or difficulty reading participants' answers, we provided answers with checkboxes for every question except for the computer usage question.

Next, in order to survey students, we had to have our research project approved by our university's Institutional Review Board. This process included an extensive application requiring a description of potential participants, reason for research, research plan, survey instrument, and how the participation of students would be used. Shortly after submission, our application was approved, allowing us to reach out to local schools and begin our surveying.

Third, we conducted a trial run of the survey by asking seven high schools students to take the survey and report any suggestions for improvement or problems comprehending the questions. Fourth, we distributed copies of the surveys to high schools in the area. We contacted principals to get their permission and delivered them to the schools that were willing to participate. The following pieces of data were collected: hours spent using an electronic devices on school days and non schools (for educational, entertainment or other purposes), SAT score, ACT score, GPA, age, gender and opinion of the effect of technology on their personal learning on a 7 point Likert Scale.

Before analyzing the survey data, we prepared the data for analysis. We converted non-numerical data into a comparable numerical format. We declared 1 as representing Male and 2 representing Female. We used $1-7$ to represent strongly disagree to strongly agree on the Likert scale. We assigned numbers to the ranges of ACT and SAT scores starting at 1 for the lowest range and ending at 13 for ACT and 14 for SAT. For GPA, we assigned numbers for the ranges, 1 for less than 2.0, 2 for $2.0-2.49,3$ for $2.5-2.99,4$ for $3.0-3.49$ and 5 for $3.5-4.0$. We then used SPSS to determine correlation between both GPA and standardized test scores and computer usage and GPA.

We analyzed our data using a T-test For Equality of the Means to compare each region to the significant region of the Midwest. We consider this region to be significant because it is where our survey data is collected. The analysis of our survey data and SAT and ACT collected data is discussed in the next section. 


\section{Issues in Information Systems}

Volume 13, Issue 1, pp. 225-231, 2012

1. How many hours do you use electronic devices (computer, smart phone, tablets, Kindle) a day?

\begin{tabular}{|c|c|}
\hline School Days & Non-School Days \\
\hline Total hours per day: ___ hours & Total hours per day: ___ hours \\
\hline Of those total hours, how many are for & Of those total hours, how many are for \\
\hline Entertainment: ___ hours & Entertainment: ___ hours \\
\hline $\begin{array}{l}\text { School: } \quad \text { hours } \\
\text { Other: } \quad \text { hours }\end{array}$ & $\begin{array}{l}\text { School: } \quad \text { hours } \\
\text { Other: }\end{array}$ \\
\hline
\end{tabular}

2. Electronic devices help improve my academic performance. (Please circle one)

Strongly Disagree Moderately Disagree Disagree Neutral Agree Moderately Agree Strongly Agree

3. What was your Composite ACT score?

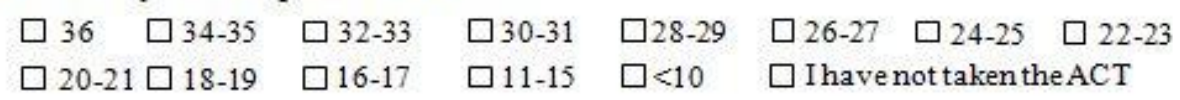

4. What was your Combined SAT score?

$\begin{array}{lllll}\square>2200 & \square 2100-2199 & \square 2000-2099 & \square 1900-1999 & \square 1800-1899 \\ \square 1700-1799 & \square 1600-1699 & \square 1500-1599 & \square 1400-1499 & \square 1300-1399 \\ \square 1200-1299 & \square 1100-1199 & \square 1000-1099 & \square<1000 & \square \text { Ihavenot taken } \\ \text { the SAT }\end{array}$

5. What is your unweighted GPA?
$3.5-4.0$
$3.0-3.49$
$\square 2.5-2.99$
$2.0-2.49$
$<2.0$

6. What is your age:

7. What is your gender:

$\square$ Male $\quad \square$ Female

8. What grade are you in?

$\square 9 \quad \square 10 \quad \square 11 \quad \square 12$

Figure 1. Survey

\section{Archival Data}

RESULTS

We used the years 1972 - 1987 to represent prior to popular computer use and the years 1995 - 2010 to represent the emergence of computer technology and increased use of it for educational or other purposes. Using SPSS, we found significant negative relationships between these time periods with both Spearman's and Pearson's correlation tests. The Spearman test between these two 15 year periods of scores was -.859 and (p-value $=0.01$ ). The Pearson test between these time periods was $-.764(\mathrm{p}$-value $=0.01)$.

We graphed the Combined Verbal and Math scores for both the pre-computing time period (1972 - 1987) and for the with-computing time period $(1995$ - 2010). Figure 1 below shows the National SAT score trend for a fifteen year period before computing was prevalent among high school students (1972 - 1987). The data illustrates a negative trend for this time period. Figure 2 below shows the National SAT score trend for the fifteen year period 


\section{Issues in Information Systems}

Volume 13, Issue 1, pp. 225-231, 2012

with computing among high school students $(1995$ - 2010). The data for this time period illustrates an initial upward trend for the first ten years.

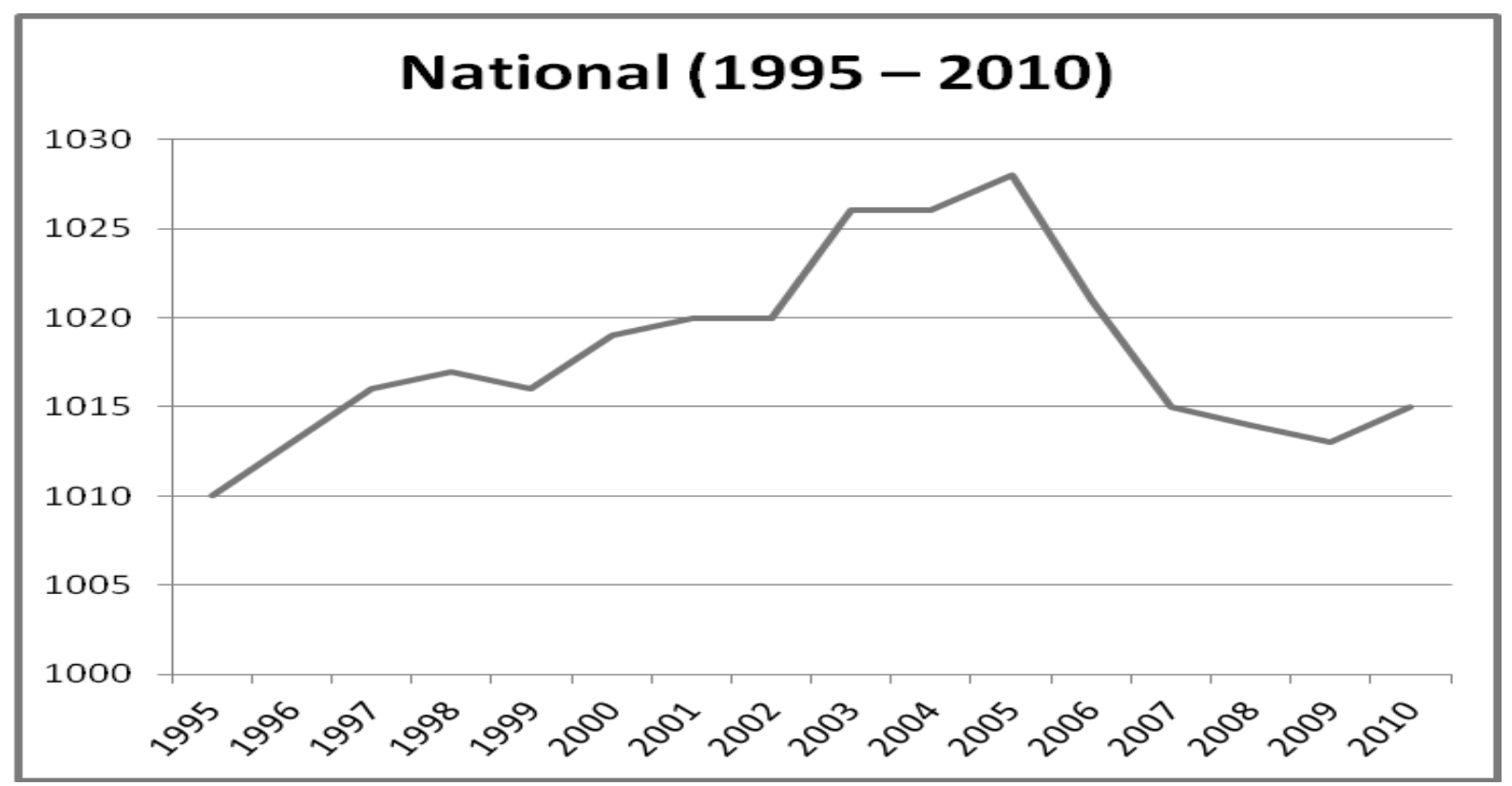

Figure 2. National SAT scores from 1972-1987

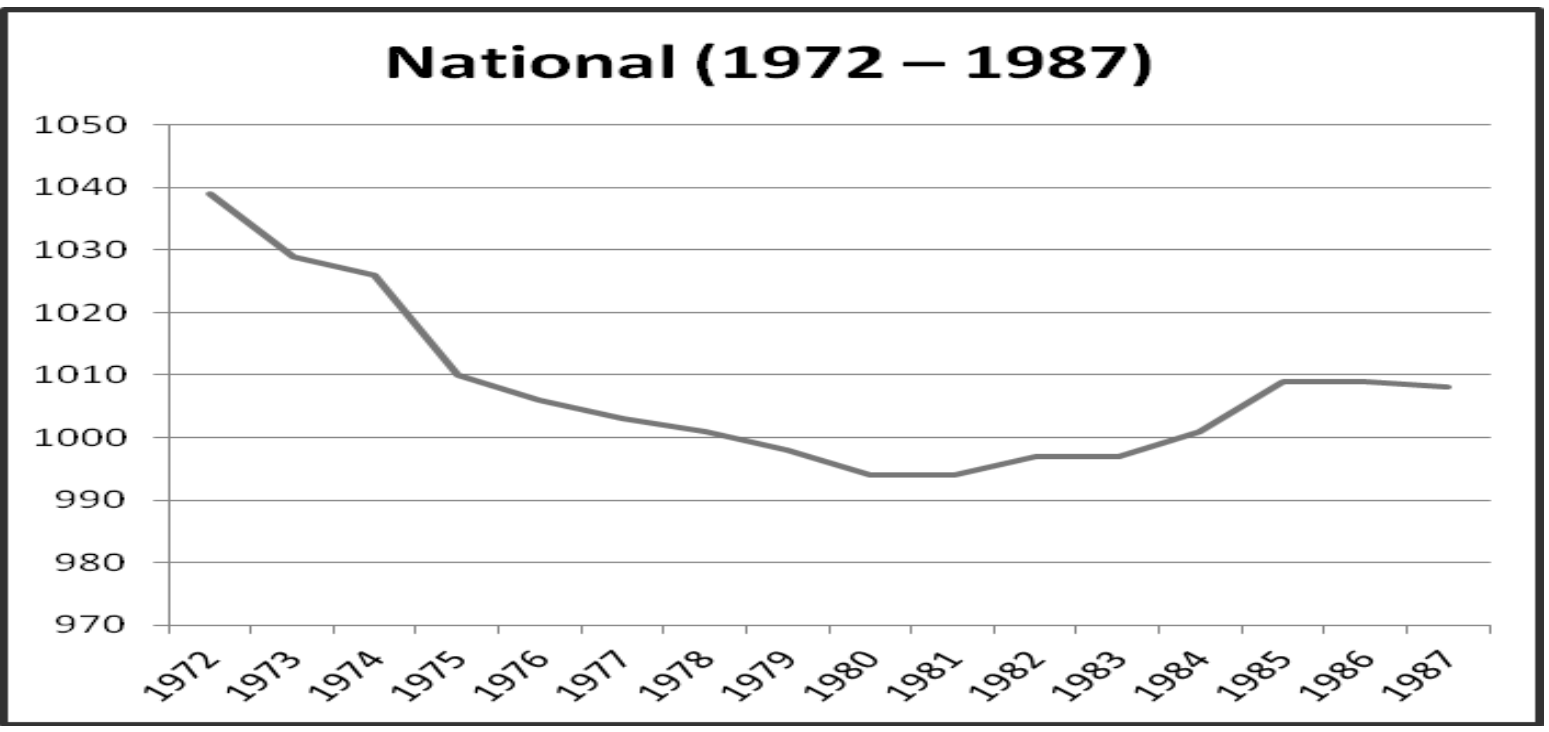

Figure 3. National SAT scores from 1995-2010

\section{Survey Data}

102 complete surveys were returned and the demographics of the respondents are shown in Table 1. The sample population had slightly more males $(52 \%)$ than females (48\%). The sample population had various ages including 12 years $(1 \%), 14$ years $(14.7 \%), 15$ years $(26.5 \%), 16$ years $(20.6 \%), 18$ years $(21.6 \%)$, and 19 years $(1 \%)$. We had students from four grades; $9^{\text {th }}$ had $33(32.45), 10^{\text {th }}$ had $29(28.4 \%), 11^{\text {th }}$ had $10(9.8 \%)$, and $12^{\text {th }}$ had $31(30.4 \%)$. Students spent an average of 5.36 hours using computer technology on school days and 8.45 hours on non-school days. 


\section{Issues in Information Systems}

Volume 13, Issue 1, pp. 225-231, 2012

Table 1. Demographics of the Respondents

\begin{tabular}{|cc|rc|cc|}
\hline Gender & & Age & & Avg Comp Use & \\
Female & $49(48 \%)$ & 12 & $1(1 \%)$ & School Days & $5.36 \mathrm{hrs}$ \\
Male & $53(52 \%)$ & 14 & $15(14.7 \%)$ & Std. Deviation & 3.91 \\
\cline { 1 - 4 } Grade & & 15 & $27(26.5 \%)$ & & \\
$9^{\text {th }}$ & $33(32.4 \%)$ & 16 & $21(20.6 \%)$ & Non-School Days & $8.45 \mathrm{hrs}$ \\
$10^{\text {th }}$ & $29(28.4 \%)$ & 17 & $15(14.7 \%)$ & Std. Deviation & 4.81 \\
$11^{\text {th }}$ & $10(9.8 \%)$ & 18 & $22(21.6 \%)$ & & \\
$12^{\text {th }}$ & $31(30.4 \%)$ & 19 & $1(1 \%)$ & & \\
\hline
\end{tabular}

We analyzed our data with SPSS and ran tests against variables in order to note correlation among factors that were recorded in our survey data. Several significant relationships were evident in our survey data. All of the results listed below use Spearman's correlation test between two variables. We had a .223 positive correlation between reported GPA and Computer Use for School on School Days (p-value $=.05$ ). There was a .213 positive correlation between GPA and Computer Use for Other on School Days (p-value =.05). No significant correlation was found between computer use for school on Non-School Days and GPA, due to the fact that the majority of our respondents reported that they did not spend any hours on schoolwork on Non-School Days. We found a .663 positive correlation between GPA and ACT scores (p-value $=.01$ ). We also found a positive correlation of .224 between GPA and sex. Finally, we found a .241 positive correlation between students that felt that computer use was beneficial to their personal academic performance and those that utilized technology for school purposes had a p-value of .05. Table 2 summarizes these correlations and highlights the significant correlations.

Table 2. Correlations

\begin{tabular}{|r|c|c|c|c|c|c|}
\hline School Days & GPA & p-value & ACT Score & p-value & Opinion & p-value \\
\hline Entertainment & -.125 & .237 & .084 & .657 & .030 & .778 \\
\hline School & .223 & .034 & -.070 & .714 & .241 & .020 \\
\hline Other & .213 & .044 & -.055 & .774 & -.080 & .447 \\
\hline Total Hours & .107 & .304 & .058 & .761 & .068 & .509 \\
\hline Non-School Days & & & & & & \\
\hline Entertainment & -.157 & .137 & -.033 & .863 & -.055 & .598 \\
\hline School & .099 & .352 & .027 & .889 & .061 & .561 \\
\hline Other & .085 & .428 & -.190 & .314 & -.050 & .638 \\
\hline Total Hours & .003 & .977 & -.129 & .497 & .015 & .887 \\
\hline GPA & 1 & & .663 & .000 & .010 & .920 \\
\hline
\end{tabular}

\section{CONCLUSION}

In this study, we aimed to answer the following research question, "Is the increased use of computer based technology improving the academic performance of students?" We analyzed standardized test scores, the SAT, in the years before prevalent computing $(1972-1987)$ and in the years with prevalent and ever-increasing computer use (1995 - 2010). We also surveyed local high school students asking for computer usage in hours, standardized test scores and GPA.

The analysis of SAT scores reveals an evident negative correlation. This significant correlation illustrates that in the first time period, 1972 - 1987, SAT scores were decreasing, but that in the years with computing, 1995 - 2010, scores were increasing. It can be inferred, without regarding other external factors, that computing has benefited student performance in standardized testing, specifically the SAT.

A thorough comparative analysis of our survey data indicates several significant correlations. First, the positive relationship between the hours of computer use for school purposes and GPA demonstrates the idea that use of electronic devices for school purposes benefits academic performance. Second, those with high GPA's also had high standardized test scores, such that it can be inferred that appropriate use of electronic devices also benefits students 


\section{Issues in Information Systems \\ Volume 13, Issue 1, pp. 225-231, 2012}

in their standardized testing. Finally, students who had the opinion that use of electronic devices improved their personal academic performance utilized those tools, which are shown by the significant correlation between students who held this opinion and used electronic devices for schoolwork. These significant correlations imply, in our sample, that use of computing, or electronic devices for school work and the like, benefit students in both their GPAs and their standardized test scores.

Our survey results and standardized test score analysis show an improvement in academic performance with increased computer usage. Specifically, our results show that students who spent more time using their electronic devices for school purposes did better in school than those who claimed they used their devices for other purposes. This result in our survey sample group illustrates our theory that "intelligent use" of electronic devices improves academic performance of students.

\section{LIMITATIONS AND FUTURE RESEARCH}

This study has a few limitations. First, in our analysis of standardized test scores, we decided against including the Writing section of the ACT as it made comparing scores between previous to 2005 and after 2005 inaccurate. This limited our ability to determine the improvement of devolvement of writing skills based upon increase in computer usage. Also, in our analysis of standardized test scores we did not include ACT scores in our results section because there was a very narrow amount of data available before prevalent computer use. Finally, we only surveyed students in local area high schools. In order to make a more accurate and generalized conclusion, we would need to have a further reaching and larger survey size. Further research must be conducted in order to determine if our results could be duplicated in another sample group and to rule out external factors.

\section{REFERENCES}

1. ACT Incorporated. (2012). ACT national and state scores. Retrieved from http://www.act.org/newsroom/data/

2. Beltran, D. (2008). Home computers and educational outcomes: Evidence from the NLSY97 and CPS. Retrieved from Board of Governors of the Federal Reserve System Web site: http://www.federalreserve.gov/pubs/ifdp/2008/958/ifdp958.pdf

3. Clark, N. (2011). Annual computer sale to pass 1 billion by 2014. Retrieved from The Independent Web site: http://www.independent.co.uk/news/business/news/annual-computer-sales-to-pass-1-billion-by-20142187923.html

4. Collegeboard.org Incorporated. (2012). Retrieved from http://professionals.collegeboard.com/data-reportsresearch/sat/archived

5. Delgado-Hachey, Maria, et al. (2005). Adolescent computer use and academic achievement. Adolescence, 40(158), 307-318.

6. Epstein, Z. (2011). IMS: Annual smartphone sales to reach 1 billion units by 2016; Apple, Samsung winners so far. Retrieved from BGR Web site: http://www.bgr.com/2011/07/27/ims-annual-smartphone-sales-to-reach-1billion-units-by-2016-apple-samsung-winners-so-far/

7. Ferguson, S. (2005). How computers make our kids stupid. Retrieved from MacLeans Web site: http://www.macleans.ca/education/universities/article.jsp?content=20050606_106930_106930

8. Subrahmanyam, K. (2001). The impact of computer use on children's and adolescents' development. Retrieved from Science Direct Web site: http://www.sciencedirect.com/science/article/pii/S0193397300000630 